\title{
Dietary inclusion of a partially defatted black soldier fly (Hermetia illucens) larva meal in low fishmeal-based diets for rainbow trout (Oncorhynchus mykiss)
}

Christian Caimi ', Ilaria Biasato', Giulia Chemello', Sara Bellezza Oddon', Carola Lussiana', Vanda Maria Malfatto', Maria Teresa Capucchio 2,3, Elena Colombino², Achille Schiavone², Francesco Gai ${ }^{3}$, Angela Trocino ${ }^{4}$,

Alberto Brugiapaglia ${ }^{1}$, Manuela Renna ${ }^{2^{*}}$ (D) and Laura Gasco ${ }^{1}$

\begin{abstract}
Background: Recent investigations highlighted that Hermetia illucens (BSF) larva meal can be a valuable alternative protein source for aquafeed production. In this study, in substitution of fishmeal, we used increasing inclusion levels of a partially defatted BSF larva meal in low fishmeal-based diets for rainbow trout (Oncorhynchus mykiss Walbaum) and we evaluated the related implications in terms of growth performance, physical characteristics, proximate and fatty acid (FA) compositions of the fillets, gut and liver histology, and diet digestibility. In a 131-day trial, 576 fish $(100.1 \pm 9.29 \mathrm{~g})$ were randomly allotted to 24 tanks (24 fish/tank, 4 replicates/treatment). Six experimental diets were produced to have partial replacement of fishmeal $(0,10 \%, 20 \%, 30 \%, 40 \%$ and $50 \%)$ by increasing levels of BSF meal (0\% [BSF0], 3\% [BSF3], 6\% [BSF6], 9\% [BSF9], 12\% [BSF12] and 15\% [BSF15] on as fed basis, respectively).

Results: No differences were observed among the treatments for all the considered growth performance parameters. The viscero and hepato-somatic indexes showed significant differences among the treatments, with the highest values observed in the BSF15 group. No differences were recorded in terms of fillet's physical characteristics, dry matter (DM), crude protein (CP) and ether extract (EE) contents. Total saturated and monounsaturated FA increased, while polyunsaturated FA (particularly n-3 FA) decreased while increasing the HI meal inclusion in the diet. Histopathology of liver and gut was not affected, whereas, in posterior gut, villi were higher in BSF6 and BSF9 compared to BSF3 fish. The apparent digestibility of DM, CP, EE and gross energy did not vary among the treatments.
\end{abstract}

Conclusions: These results suggest that a partially defatted BSF meal could be included up to 15\% in low fishmeal-based diets for rainbow trout with no adverse effects on growth performance, fillet's physical characteristics, gut and liver health, and diet digestibility. On the contrary, the fillet FA composition worsened while increasing the level of BSF meal in the diet.

Keywords: Apparent digestibility coefficient, Chemical and physical characteristics of fillets, Fatty acid profile, Fishmeal substitution, Hermetia illucens meal, Histopathology, Performance

\footnotetext{
* Correspondence: manuelarenna@unito.it

${ }^{2}$ Department of Veterinary Sciences, University of Turin, Largo P. Braccini 2,

10095 Grugliasco, TO, Italy

Full list of author information is available at the end of the article
}

(c) The Author(s). 2021 Open Access This article is licensed under a Creative Commons Attribution 4.0 International License, which permits use, sharing, adaptation, distribution and reproduction in any medium or format, as long as you give appropriate credit to the original author(s) and the source, provide a link to the Creative Commons licence, and indicate if changes were made. The images or other third party material in this article are included in the article's Creative Commons licence, unless indicated otherwise in a credit line to the material. If material is not included in the article's Creative Commons licence and your intended use is not permitted by statutory regulation or exceeds the permitted use, you will need to obtain permission directly from the copyright holder. To view a copy of this licence, visit http://creativecommons.org/licenses/by/4.0/ The Creative Commons Public Domain Dedication waiver (http://creativecommons.org/publicdomain/zero/1.0/) applies to the data made available in this article, unless otherwise stated in a credit line to the data. 


\section{Background}

In the next few years, there will be an increase in the global demand of protein because of the constant increase in the world population [1]. Aquaculture has the fastest growing in the food production, with an average annual rate above 5.5\% per year [2] and, for this reason, is considered as one of the livestock sectors able to support the global demand of animal products [3]. The growing in fish production leads to an increase in the demand of aquaculture feeds. For many years, fishmeal (FM) has been the preferred protein source for the production of aquafeeds due to its valuable content of protein and fatty acids (FA), amino acid profile, high digestibility and palatability [4]. However, the constant increase of the demand of aquaculture feeds has led to a rapid growth in the FM price and to a negative impact on the marine ecosystem [5]. In order to maintain the correct percentage of protein to meet the nutritional requirements of fish, in the last 20 years FM has been partially replaced with alternative raw materials, such as vegetable protein sources and processed animal proteins (PAPs), leading to a reduction in the dietary FM inclusion in the feeds.

Recently, in order to replace FM, the attention has been focused on the use of insect-derived PAPs. Insects can be used to produce high quality ingredients, rich in protein and fat, starting from waste biomass and with low environmental impact [6, 7]. One of the insect species with the highest potential to be used in fish feeds is the black soldier fly (Hermetia illucens L.) (BSF). The larvae of this fly can be reared on low value organic waste, with low water demand and generating low greenhouse gas emissions [8]. Generally, the meals obtained from BSF show a protein content ranging from $37 \%$ to $63 \%$, and a fat content from $7 \%$ to $39 \%$ on a dry matter (DM) basis $[9,10]$.

Despite the nutritional value of $B S F$ meal, its successful inclusion level in aquafeeds depends also on their effect on gut health and liver integrity, which are fundamental for nutrient digestion and absorption and thus for growth performances [11]. For this reason, gut histomorphometry and liver histopathology are usually taken into account when alternative ingredients are investigated in animal nutrition [12]. Nutritional studies on the total and partial substitution of FM with BSF meal have been previously conducted in rainbow trout (Oncorhynchus mykiss Walbaum). A recent study by Cardinaletti et al. [12] showed that in a control diet containing $42 \%$ of FM, the $50 \%$ of the FM could be replaced including a dietary inclusion up to $21 \%$ of a full-fat BSF meal without negative effects on the growth performance of rainbow trout. However, a decrease in villus height and an increase in liver lipid accumulation was observed in trout fed BSF meal. Compared to a control diet with a
FM dietary inclusion of $60 \%$, Renna et al. [13] showed that an inclusion up to $40 \%$ of partially defatted BSF meal could replace up to $50 \%$ of FM without any adverse effects on growth performance, gut and liver histomorphometry. On the contrary, studies by Dumas et al. [14] and St-Hilaire et al. [15], using a defatted BSF meal (up to $26.4 \%$ of inclusion) and a full-fat BSF meal (up to $29.8 \%$ of inclusion), respectively, showed a worsening of the growth performance of trout at increasing BSF inclusion levels. The growth performance and the gut and liver histopathology reported in these studies showed contradictory results probably due to several factors, such as the nutritional composition and inclusion level of the insect meal, and fish size.

As we can see in literature, most of the studies performed in fish nutrition replacing FM with BSF meal have been conducted using control diets with high levels of FM, usually higher than $30 \%[13,16-20]$. However, due to the current price of FM, only $10-20 \%$ of FM is currently included in commercial diets $[2,21]$.

Therefore, the aim of this study was to determine the potential of six inclusion levels of a partially defatted BSF larva meal as a partial replacer of FM in low FMbased diet, on growth performance, somatic indexes, fillet's physical characteristics, proximate composition and FA profile, histopathological investigation of gut and liver, and digestibility in rainbow trout.

\section{Methods}

The experimental protocol was designed according to the guidelines of the current European Directive on the protection of animals used for scientific purposes (2010/ 63/EU) and approved by the Ethical Committee of the University of Turin (Italy) (protocol $n^{\circ} 143811$ ). The trial was carried out at the Experimental Facility of the Department of Agricultural, Forest and Food Sciences (DISAFA) of the University of Turin (Italy).

\section{Experimental diets}

Six experimental diets were formulated to be isonitrogenous (crude protein - CP: about $45.8 \mathrm{~g} / 100 \mathrm{~g}$ as fed), isolipidic (ether extract - EE: about $15.2 \mathrm{~g} / 100 \mathrm{~g}$ as fed), and isoenergetic (gross energy - GE: about $22.6 \mathrm{MJ} / \mathrm{kg}$ as fed). The six diets were obtained including, as fed basis, increasing levels of a partially defatted BSF larva meal $-0,3 \%, 6 \%, 9 \%, 12 \%$ and $15 \%$ - corresponding to a substitution of $0 \%$ (BSF0), 10\% (BSF3), 20\% (BSF6), 30\% (BSF9), 40\% (BSF12) and 50\% (BSF15) of FM. The BSF larva meal used in this study was provided by MUTATEC (Caumont-sur-Durance, France). The larvae had been raised on plant by-products and partially defatted using a mechanical process. Unfortunately, no other information was given by the producer about either the rearing substrate or the processing methodologies, as 
this information is considered confidential. The experimental diets were prepared at the Experimental Facility of DISAFA. All the ground ingredients and oils were individually weighed (KERN PLE-N v.2.2; KERN \& Sohn $\mathrm{GmbH}$, Balingen-Frommern, Germany; d: 0.01) and mixed with a blender (Brevetti S.A.G.A., Milano, Italy). To facilitate the pelleting process, an amount of 250 to $500 \mathrm{~mL} / \mathrm{kg}$ of water was added to the mixture. The pelletizing was performed using a meat grinder (LABOR 32; Rheninghaus Factory, San Mauro Torinese, Italy). The pellets $(3.0 \mathrm{~mm})$ were subsequently dried $\left(50^{\circ} \mathrm{C}\right.$ for $48 \mathrm{~h}$ ) and stored in black bags at $-20^{\circ} \mathrm{C}$ until used. The ingredients of the experimental diets are reported in Table 1.

\section{Chemical analyses of BSF meal and experimental diets}

The proximate composition and the energy level of the BSF meal and experimental diets were measured in duplicate at the DISAFA laboratories. Feed samples were ground using a cutting mill (MLI 204; Bühler AG, Uzwil, Switzerland) and analysed for DM (AOAC \#934.01), CP (AOAC \#984.13) and ash (AOAC \#942.05) contents according to AOAC International [22]; EE (AOAC \#2003.05) was analysed according to AOAC International
[23]. The GE content was determined using an adiabatic calorimetric bomb (C7000; IKA, Staufen, Germany). The chitin content of BSF meal was estimated according to Finke [24] by correction considering the AA content of the acid detergent fiber (ADF) fraction and assuming the remainder of the ADF fraction is chitin. Due to the presence of vegetable raw material in the diets, the method proposed by Finke [24] cannot be applied to calculate the chitin content of the diets. For this reason, the amount of chitin of the experimental diets was estimated based on the chitin content of the BSF meal and its inclusion level in the diets.

The AA determination of BSF larva meal and experimental diets was performed according to the method described in De Marco et al. [25]. After a 22-h hydrolysis step in $6 \mathrm{~mol} / \mathrm{L} \mathrm{HCl}$ at $112{ }^{\circ} \mathrm{C}$ under a nitrogen atmosphere, the AA content in hydrolysate was determined by means of HPLC after postcolumn derivatization. Performic acid oxidation occurred prior to acid hydrolysis for methionine and cysteine. Tryptophan was not determined. The AA composition is shown in Table 2.

A combined direct trans-esterification and solid-phase extraction was carried out for the determination of the fatty acid profile of the BSF meal and experimental diets,

Table 1 Ingredients and proximate composition of the experimental diets and BSF larva meal

\begin{tabular}{|c|c|c|c|c|c|c|c|}
\hline & BSF & BSF0 & BSF3 & BSF6 & BSF9 & BSF12 & BSF15 \\
\hline \multicolumn{8}{|l|}{ Ingredients, \% } \\
\hline Fishmeal $^{\mathrm{a}}$ & & 20.0 & 18.0 & 16.0 & 14.0 & 12.0 & 10.0 \\
\hline Hermetia illucens larva meal ${ }^{b}$ & & - & 3.0 & 6.0 & 9.0 & 12.0 & 15.0 \\
\hline Wheat gluten & & 13.0 & 13.0 & 13.0 & 13.0 & 13.0 & 13.0 \\
\hline Soybean meal & & 20.0 & 20.0 & 20.0 & 20.0 & 20.0 & 20.0 \\
\hline Swine haemoglobin & & 9.2 & 9.0 & 8.8 & 8.6 & 8.4 & 8.2 \\
\hline Wheat starch & & 23.4 & 22.6 & 21.8 & 21.0 & 20.2 & 19.4 \\
\hline Fish oil & & 7.0 & 7.0 & 7.0 & 7.0 & 7.0 & 7.0 \\
\hline Soybean oil & & 7.0 & 7.0 & 7.0 & 7.0 & 7.0 & 7.0 \\
\hline Minerals ${ }^{c}$ & & 0.25 & 0.25 & 0.25 & 0.25 & 0.25 & 0.25 \\
\hline Vitamins $^{d}$ & & 0.20 & 0.20 & 0.20 & 0.20 & 0.20 & 0.20 \\
\hline \multicolumn{8}{|l|}{ Chemical composition ${ }^{\mathrm{e}}$} \\
\hline Dry matter, g/100 g & 94.0 & 97.2 & 97.2 & 96.9 & 96.8 & 96.9 & 96.6 \\
\hline Ash, $\mathrm{g} / 100 \mathrm{~g}$ as fed & 10.2 & 5.8 & 5.9 & 5.8 & 5.7 & 5.5 & 5.5 \\
\hline Crude protein, g/100 g as fed & 56.9 & 45.6 & 46.1 & 45.6 & 46.0 & 45.7 & 46.1 \\
\hline Ether extract, $\mathrm{g} / 100 \mathrm{~g}$ as fed & 7.0 & 14.9 & 15.9 & 15.8 & 15.7 & 14.6 & 14.3 \\
\hline Gross energy, MJ/kg as fed & 20.2 & 22.4 & 22.7 & 22.6 & 22.7 & 22.7 & 22.6 \\
\hline Chitin, g/100 g & 6.3 & - & 0.18 & 0.37 & 0.56 & 0.75 & 0.93 \\
\hline
\end{tabular}

Abbreviations: BSF Hermetia illucens. ${ }^{a}$ Purchased from Skretting Italia S.p.A. (Località Vignetto, 17-37060 Mozzecane VR, Italy). Proximate composition (g/100 g, as fed): DM 91.0, CP 67.6, EE 8.3, Ash 16.4. ${ }^{b}$ Provided by MUTATEC (Caumont-sur-Durance, France). ${ }^{\mathrm{C}}$ Mineral mixture (g/kg or mg/kg diet): dicalcium phosphate, 500 g; calcium carbonate, $215 \mathrm{~g}$; sodium salt, $40 \mathrm{~g}$; potassium chloride, $90 \mathrm{~g}$; magnesium chloride, $124 \mathrm{~g}$; magnesium carbonate, $124 \mathrm{~g}$; iron sulphate, $20 \mathrm{~g}$; zinc sulphate, $4 \mathrm{~g}$; copper sulphate, $3 \mathrm{~g}$; potassium iodide, $4 \mathrm{mg}$; cobalt sulphate, $20 \mathrm{mg}$; manganese sulphate, $3 \mathrm{~g}$; sodium fluoride, $1 \mathrm{~g}$ (purchased from Granda Zootecnici S.r.l., Cuneo, Italy). ${ }^{d}$ Vitamin mixture (IU/kg or $\mathrm{mg} / \mathrm{kg}$ diet): $D L$-a-tocopherol acetate, 60 IU; sodium menadione bisulphate, $5 \mathrm{mg}$; retinyl acetate, 15,000 IU; DL-cholecalciferol, 3000 IU; Stay C Roche (vitamin C), 90 mg; thiamin, 15 mg; riboflavin, 30 mg; pyridoxine, 15 mg; vitamin B $12,0.05$ mg; nicotinic acid, 175 mg; folic acid, 500 mg; inositol, 1000 mg; biotin, 2.5 mg; calcium panthotenate, 50 mg (purchased from Granda Zootecnici S.r.l., Cuneo, Italy). ${ }^{\text {e } V a l u e s ~ a r e ~ r e p o r t e d ~ a s ~}$ mean of duplicate analyses 
Table 2 Amino acid (AA) concentration ( $\mathrm{g} / 100 \mathrm{~g}$ of protein) of BSF meal and experimental diets

\begin{tabular}{|c|c|c|c|c|c|c|c|}
\hline & BSF & BSF0 & BSF3 & BSF6 & BSF9 & BSF12 & BSF15 \\
\hline \multicolumn{8}{|l|}{ Essential AA } \\
\hline Arginine & 3.9 & 5.3 & 5.2 & 5.2 & 5.1 & 5.0 & 5.0 \\
\hline Histidine & 2.2 & 2.8 & 2.8 & 2.8 & 2.8 & 2.7 & 2.9 \\
\hline Isoleucine & 3.3 & 3.5 & 3.4 & 3.4 & 3.3 & 3.3 & 3.3 \\
\hline Leucine & 5.2 & 7.7 & 7.5 & 7.5 & 7.3 & 7.2 & 7.1 \\
\hline Lysine & 3.8 & 5.9 & 5.6 & 5.5 & 5.3 & 5.2 & 5.0 \\
\hline Methionine & 2.6 & 2.5 & 2.5 & 2.5 & 2.5 & 2.5 & 2.6 \\
\hline Cysteine & 1.3 & 1.3 & 1.2 & 1.1 & 1.1 & 1.0 & 1.3 \\
\hline Phenylalanine & 3.0 & 4.6 & 4.6 & 4.5 & 4.5 & 4.4 & 4.3 \\
\hline Tyrosine & 4.8 & 3.0 & 3.0 & 3.1 & 3.1 & 3.2 & 3.2 \\
\hline Threonine & 3.1 & 7.6 & 7.6 & 7.6 & 7.6 & 7.6 & 7.6 \\
\hline Valine & 4.9 & 3.5 & 3.5 & 3.4 & 3.4 & 3.3 & 3.3 \\
\hline \multicolumn{8}{|l|}{ Non-essential AA } \\
\hline Alanine & 6.2 & 4.8 & 4.8 & 4.8 & 4.8 & 4.8 & 4.8 \\
\hline Aspartic acid & 6.7 & 8.1 & 7.9 & 7.9 & 7.7 & 7.7 & 7.6 \\
\hline Glycine & 4.2 & 2.7 & 2.8 & 2.9 & 3.0 & 3.1 & 3.2 \\
\hline Glutamic acid & 8.8 & 16.0 & 15.9 & 16.1 & 16.1 & 16.3 & 16.2 \\
\hline Proline & 5.5 & 8.5 & 8.2 & 8.1 & 7.8 & 7.6 & 7.4 \\
\hline Serine & 3.7 & 3.7 & 3.6 & 3.7 & 3.6 & 3.6 & 3.6 \\
\hline
\end{tabular}

Abbreviations: BSF Hermetia illucens

using eptadecanoic acid as internal standard, as reported in Dabbou et al. [26]. Fatty acid methyl esters (FAME) were separated, identified and quantified as reported in Dabbou et al. [27]. The results are expressed as mg/100 g DM and are reported in Table 3.

All the chemical analyses of feed were performed in duplicate.

\section{Fish and rearing conditions}

A 131-day growth trial was carried out with rainbow trout purchased from a private fish hatchery ("Troticoltura Bassignana", Cuneo, Italy). An acclimatization period of two weeks was provided during which the fish were fed a commercial diet $(42 \mathrm{~g} / 100 \mathrm{~g}$ as fed of CP; $22 \mathrm{~g} / 100 \mathrm{~g}$ as fed of EE; Skretting Italia Spa, Mozzecane (VR), Italy). Then a total of 576 fish were lightly anesthetised $(60 \mathrm{mg} / \mathrm{L} \mathrm{MS}-$ 222 - PHARMAQ Ltd., Fordingbridge, Hampshire, UK), individually weighed (mean individual initial body weight - iIBW: $100.1 \pm 9.29$ g; KERN PLE-N v.2.2; KERN \& Sohn $\mathrm{GmbH}$, Balingen-Frommern, Germany; d: 0.01) and randomly divided into 24 fiberglass 200-L tanks (four replicate tanks per diet, twenty-four fish per tank). Artesian well water (constant temperature of $13 \pm 1{ }^{\circ} \mathrm{C}$ ) was supplied in flow-through open system with each tank having a water inflow of $8 \mathrm{~L} / \mathrm{min}$. Dissolved oxygen was measured every week and ranged between 7.6 and $8.7 \mathrm{mg} / \mathrm{L}$. Feed was distributed by hand twice a day, six days per week (number of feeding days =
121). The fish were fed $1.4 \%$ of the tank biomass. Feed intake was checked at each administration and feed administration was stopped as soon as the fish stopped eating. In order to update the daily quantity of feed, the fish were weighed in bulk every 14 days. Mortality was checked every day.

\section{Growth performance}

At the end of the trial, after $24 \mathrm{~h}$ of fasting, all the fish were lightly anesthetised and individually weighed. The following performance indexes were calculated:

- Mortality $(\%)=($ number of dead fish $/$ initial number of fish) $\times 100$

- Individual weight gain (iWG, g) = iFBW (average individual final body weight, g) - iIBW (average individual initial body weight, g)

- Specific growth rate $(\mathrm{SGR}, \% / \mathrm{d})=[(\mathrm{InFBW}-$ InIBW) / number of feeding days] $\times 100$

- Feed conversion ratio $(\mathrm{FCR})=$ total feed supplied ( $\mathrm{g}$, DM) / WG (g)

- Protein efficiency ratio (PER) = WG (g) / total protein fed (g DM).

Individual initial and final body weight were used to calculate the iWG while SGR, FCR and PER were calculated per tank. 
Table 3 Fatty acid profile (mg/100 g DM) of BSF larva meal and experimental diets

\begin{tabular}{|c|c|c|c|c|c|c|c|}
\hline & BSF & BSF0 & BSF3 & BSF6 & BSF9 & BSF12 & BSF15 \\
\hline C10:0 & 67.8 & 43.8 & 60.3 & 73.4 & 91.0 & 49.7 & 63.2 \\
\hline C12:0 & 1898.7 & 6.94 & 64.7 & 101.1 & 177.9 & 228.4 & 291.4 \\
\hline C14:0 & 483.0 & 413.6 & 436.2 & 446.7 & 465.6 & 450.9 & 475.8 \\
\hline C15 iso & 4.51 & 13.2 & 14.3 & 13.5 & 13.3 & 13.4 & 13.4 \\
\hline C15 aiso & 5.74 & 4.62 & 4.63 & 4.54 & 4.12 & 4.24 & 4.34 \\
\hline C14:1 c-9 + C15:0 & 27.0 & 39.0 & 41.3 & 41.2 & 40.8 & 39.0 & 41.1 \\
\hline C16 iso & 1.90 & 1.50 & 3.19 & 1.92 & 2.34 & 2.16 & 2.10 \\
\hline C16:0 & 1111.4 & 1901.7 & 1980.2 & 2072.9 & 2058.6 & 1966.5 & 2060.0 \\
\hline $\mathrm{C} 17$ iso & 2.83 & 37.1 & 40.8 & 31.5 & 29.4 & 29.1 & 30.0 \\
\hline C17 aiso & 29.8 & 11.5 & 18.6 & 7.66 & 4.75 & 5.85 & 6.20 \\
\hline C16:1 c-9 & 174.5 & 488.8 & 504.4 & 365.8 & 281.3 & 287.0 & 316.5 \\
\hline C17:1 c-9 & 8.16 & 14.9 & 18.5 & 10.3 & 8.06 & 8.38 & 9.06 \\
\hline C18:0 & 246.8 & 548.9 & 562.0 & 553.9 & 537.9 & 513.9 & 538.7 \\
\hline C18:1 $t$ & 14.5 & 11.0 & 11.0 & 9.43 & 9.24 & 9.13 & 10.9 \\
\hline C18:1 c-9 & 1216.0 & 2078.2 & 2171.7 & 1658.9 & 1278.1 & 1332.4 & 1530.6 \\
\hline C18:1 c-11 & 27.8 & 273.8 & 281.1 & 209.8 & 161.8 & 162.4 & 179.4 \\
\hline C18:1 c-12 & 0.32 & 6.22 & 3.49 & 1.25 & 1.43 & 1.00 & 1.16 \\
\hline$C 18: 1 c-14+t-16$ & 4.42 & 11.41 & 8.85 & 5.38 & 4.79 & 4.16 & 5.01 \\
\hline C18:2 n-6 & 403.4 & 2381.2 & 2486.6 & 533.1 & 398.4 & 387.7 & 418.5 \\
\hline C18:3 n-3 & 26.0 & 241.3 & 244.8 & 30.4 & 24.3 & 22.7 & 21.7 \\
\hline C18:3 n-6 & 1.56 & 10.0 & 10.1 & 1.89 & 2.05 & 1.01 & 0.28 \\
\hline C20:0 & 20.0 & 34.6 & 34.2 & 40.0 & 35.1 & 37.7 & 41.8 \\
\hline$C 20: 1$ c-9 & 4.34 & 67.1 & 65.4 & 55.3 & 44.5 & 43.7 & 47.1 \\
\hline$C 20: 1$ c-11 & n.d. & 2.02 & 2.08 & 0.10 & 0.54 & 0.19 & 0.35 \\
\hline$C 20: 2 n-6$ & n.d. & 62.3 & 59.3 & 6.37 & 4.53 & 4.75 & 3.91 \\
\hline$C 20: 3 n-6$ & n.d. & 2.44 & 3.49 & 0.60 & 0.17 & 0.87 & 0.33 \\
\hline$C 20: 3 n-3$ & n.d. & 13.4 & 8.40 & 4.90 & 2.89 & 3.22 & 2.89 \\
\hline C20:4 n-6 & 1.11 & 25.3 & 24.0 & 4.28 & 2.75 & 2.76 & 1.89 \\
\hline$C 20: 5 n-3$ & n.d. & 298.8 & 275.8 & 47.3 & 35.6 & 35.9 & 30.00 \\
\hline C22:0 & 11.5 & 31.9 & 26.7 & 27.8 & 28.4 & 26.6 & 26.4 \\
\hline C22:1 n-9 & n.d. & 8.39 & 8.30 & 5.87 & 4.31 & 4.63 & 4.38 \\
\hline C22:5 n-3 & n.d. & 32.9 & 29.7 & 2.15 & 1.47 & 1.70 & 2.88 \\
\hline$C 22: 6 n-3$ & n.d. & 119.3 & 151.5 & 35.9 & 23.7 & 21.9 & 19.8 \\
\hline$\Sigma$ SFA & 3866.0 & 3020.3 & 3205.5 & 3357.2 & 3435.2 & 3312.8 & 3538.4 \\
\hline$\Sigma$ MUFA & 1450.0 & 2961.7 & 3075.0 & 2322.1 & 1794.1 & 1853.0 & 2104.5 \\
\hline$\Sigma$ PUFA & 436.6 & 3186.9 & 3293.7 & 666.8 & 495.8 & 482.4 & 502.2 \\
\hline$\Sigma$ PUFA / $\Sigma$ SFA & 0.11 & 1.06 & 1.03 & 0.20 & 0.14 & 0.15 & 0.14 \\
\hline$\sum n-3$ & 26.0 & 705.8 & 710.2 & 120.5 & 87.9 & 85.3 & 77.3 \\
\hline$\sum n-6$ & 406.0 & 2481.2 & 2583.5 & 546.3 & 407.9 & 397.1 & 424.9 \\
\hline$\sum n-3 / \Sigma n-6$ & 0.06 & 0.28 & 0.27 & 0.22 & 0.22 & 0.21 & 0.18 \\
\hline TFA & 5797.4 & 9236.9 & 9655.7 & 6405.3 & 5779.0 & 5702.8 & 6201.1 \\
\hline
\end{tabular}

Abbreviations: DM dry matter, BSF Hermetia illucens, c cis, $t$ trans, SFA saturated fatty acids, MUFA monounsaturated fatty acids, PUFA polyunsaturated fatty acids, TFA total fatty acids, n.d. not detected. Values are reported as mean of duplicate analyses 
Somatic indexes, carcass yield and coefficient of fatness At the end of the trial, twenty-eight fish per treatment (seven fish per tank) were sacrificed by over anaesthesia (MS-222, PHARMAQ Ltd., Fordingbridge, Hampshire, UK; $500 \mathrm{mg} / \mathrm{L}$ ). The fish were individually weighed and then slaughtered to calculate the carcass yield (CY), the hepatosomatic index (HSI), the viscerosomatic index (VSI), and the coefficient of fatness (CF). The following formulas were used:

- $\mathrm{CY}(\%)=[$ total weight without gut and gonad (g) / fish weight $(\mathrm{g})] \times 100$

- HSI $(\%)=[$ liver weight $(\mathrm{g}) /$ fish weight $(\mathrm{g})] \times 100$

- VSI $(\%)=$ [gut weight $(\mathrm{g}) /$ fish weight $(\mathrm{g})] \times 100$

- $\mathrm{CF}(\%)=[$ perivisceral fat weight $(\mathrm{g}) /$ fish weight $(\mathrm{g})] \times 100$.

\section{Physical characteristics, proximate composition and fatty acid profile of fillets}

Nine fish per treatment were filleted, and the right fillets were weighed, packaged in a plastic bag and then refrigerated at $+4{ }^{\circ} \mathrm{C}$. After $24 \mathrm{~h}$ at $+4^{\circ} \mathrm{C}$, the right fillets were gently dried with paper to remove excess moisture, and then weighed. Subsequently, the muscle $\mathrm{pH}\left(\mathrm{pH}_{24 \mathrm{~h}}\right)$ and flesh color were assessed on the inside portion of the cranial, medial and caudal region of each fillet. The $\mathrm{pH}_{24}$ measurement was performed using a Crison MicropH 2001 (Crison Instruments, Barcelona, Spain) equipped with a combined electrode and an automatic temperature compensator. The flesh color was analysed using a bench colorimeter Chroma Meter CR-400 (Konica Minolta Sensing Inc., Osaka, Japan). The results were expressed in terms of lightness $\left(\mathrm{L}^{*}\right)$, redness $\left(\mathrm{a}^{*}\right)$ and yellowness $\left(\mathrm{b}^{*}\right)$ in the CIELAB color space model [28].

The water holding capacity was calculated as follows:

- Drip loss $(\mathrm{DL} ; \%)=[$ (raw fillet weight $(\mathrm{g})$ - raw fillet weight after $24 \mathrm{~h}(\mathrm{~g})) /$ raw fillet weight $(\mathrm{g})] \times 100$

The fillets were then individually vacuum-packaged in a plastic bag and stored at $-20^{\circ} \mathrm{C}$. After total freezing, the fillets were thawed at $+4{ }^{\circ} \mathrm{C}$, removed from the bags, dried with paper, and weighed to calculate the thawed loss (TL) as follows:

- Thawing loss $(\mathrm{TL} ; \%)=[$ (raw fillet weight $(\mathrm{g})-$ thawed fillet weight $(\mathrm{g})) /$ raw fillet weight $(\mathrm{g})] \times 100$

The same fillets were then vacuum-packaged in a plastic bag and cooked in a fish kettle for $10 \mathrm{~min}$ at $80^{\circ} \mathrm{C}$ (core temperature of the fillets: $75^{\circ} \mathrm{C}$ ). After cooking, the bags were removed from the fish kettle and cooled in fresh water for $15 \mathrm{~min}$ to stop the cooking process.
Then, the fillets were removed from the bags, dried with paper and weighed again to calculate the cooking loss (CL), as follows:

- Cooking loss $(\mathrm{CL} ; \%)=[$ (raw fillet weight $(\mathrm{g})-$ cooked fillet weight $(\mathrm{g})) /$ raw fillet weight $(\mathrm{g})] \times 100$

Following cooking loss determination, a cooked fish sample $(1.5 \mathrm{~cm} \times 1.5 \mathrm{~cm})$ from each fillet was sheared perpendicular to the fibre direction using the Instron 5543 Universal Testing Machine (Instron Corporation, Canton, Massachusetts, USA) equipped with a straight edged shear blade (crosshead speed of $30 \mathrm{~mm} / \mathrm{min}$ ). The maximum peak force recorded during the analysis was reported as Newton $(\mathrm{N})$ shear force.

The nine left fillets per treatment were frozen, finely ground with a knife mill (Grindomix GM200; Retsch $\mathrm{GmbH}$, Haan, Germany) and freeze-dried (Edwards MF 1000, Milan, Italy) to determine their proximate composition (DM, CP, EE, and ash), according to the same procedures implemented for feed analyses [23, 24]. The freeze-dried and ground samples of the fish fillet were also used to assess their FA composition. After dichloromethane-methanol extraction of total lipids from fillets, a basic saponification and a $\mathrm{BF}_{3}$ esterification were used for the determination of the fatty acid composition, adding tridecanoic acid as internal standard, as reported by Renna et al. [29]. FAME were separated using the same analytical instruments and temperature program previously reported for the FA analysis of feeds. Peaks were identified by injecting pure FAME standards as reported in Renna et al. [30]. The results were expressed as $\mathrm{mg} / 100 \mathrm{~g}$ wet weight (ww). All chemical analyses were performed in duplicate.

\section{Morphometric investigation}

Eight fish per treatment were submitted to morphometric and histopathological evaluation. Samples of anterior and posterior gut were excised and flushed with $0.9 \% \mathrm{sa}-$ line solution to remove all the content. Liver samples were also collected. The collected samples were fixed in $10 \%$ buffered formalin solution, routinely embedded in paraffin wax blocks, sectioned at $5 \mu \mathrm{m}$ thickness, mounted on glass slides and stained with Haematoxylin \& Eosin. One slide per each intestinal segment was examined by light microscopy and captured with a Nikon DS-Fi1 digital camera (Nikon Corporation, Minato, Tokyo, Japan) coupled to a Zeiss Axiophot microscope (Carl Zeiss, Oberkochen, Germania) using $2.5 \times$ objective lens. NIS-Elements $\mathrm{F}$ software was used for image capturing.

Morphometric analysis was performed by Image ${ }^{\circ}$-Pro Plus software (6.0 version, Media Cybernetics, Maryland, 
USA) on 10 well-oriented and intact villi chosen from each gut segment. The evaluated morphometric index was villus height (Vh, from the villus tip to the crypt bottom). The observed histopathological findings were evaluated in all the organs using a semi-quantitative scoring system as follows: absent $($ score $=0)$, mild $($ score $=1)$, moderate $($ score $=2)$ and severe $($ score $=3)$. Gut histopathological findings were separately assessed for mucosa (inflammatory infiltrates) and submucosa (inflammatory infiltrates and Gut-Associated Lymphoid Tissue activation) for each segment. The total score of each gut segment was obtained by adding up the mucosa and submucosa scores. All the slides were blind assessed by two independent observers and the discordant cases were reviewed, using a multi-head microscope, until unanimous consensus was reached.

\section{Digestibility trial}

In parallel with the growth trial, an in vivo digestibility experiment was performed to determine the apparent digestibility coefficients (ADC) of the diets. Two hundred and forty rainbow trout (mean individual body weight: $100.6 \pm 8.53 \mathrm{~g}$ ) were divided into twelve 250 -L cylindroconical tanks (two replicates per treatment, twenty fish per tank) connected to the same open water system of the growth trial. After 14 days of acclimatization with the experimental diets, the fish were fed by hand to visual satiation two times per day (at 8:00 and 15:00 h), six days per week. The feces were collected daily from each tank for three consecutive weeks, using a continuous automatic device (Choubert' system) as described by Palmegiano et al. [31]. To ensure the correct level of replications per treatment (i.e. $n=4$ ), the experiment was conducted over two blocked events using the same batch of fish for both blocks. Before new fecal collection commenced, the fish were allowed to acclimatize to their new diet for a period of 10 days [32]. The feces were pooled within tank, kept frozen $\left(-20^{\circ} \mathrm{C}\right)$ before being freeze dried and then refrigerated $\left(+4^{\circ} \mathrm{C}\right)$ until analysed. The ADCs were measured using the indirect acidinsoluble ash method. For this purpose, the fish were fed the same experimental diets of the growth trial, added with $1 \%$ Celite $^{\circ}$ (Fluka, St. Gallen, Switzerland) as an inert marker in substitution of $1 \%$ of wheat gluten meal. The ADC of DM, CP, EE, and GE were calculated as reported by Caimi et al. [19] and expressed as a percentage.

\section{Statistical analyses}

Data were analysed using IBM SPSS Statistics v. 25.0 for Windows. One way-ANOVA or Kruskall Wallis tests were used to compare data among the experimental groups. The assumption of normality was checked using the Kolmogorov-Smirnov test. The assumption of homoscedasticity was assessed by Levene's homogeneity of variance test. If such an assumption did not hold, the Brown-Forsythe statistic was applied to test the equality of group means instead of the $\mathrm{F}$ one. Pairwise multiple comparisons were performed to test the difference between each pair of means (Tukey's test and Tamhane's T2 in the cases of equal variances assumed or not assumed, respectively [one-way ANOVA], or Dunn's test [Kruskall-Wallis test]). The results were expressed as the mean and pooled standard error of the mean (SEM) or median and interquartile range (IR), depending on data distribution. Significance was set at $P<0.05$.

\section{Results \\ Diets}

As expected, the DM, ash, CP, EE and GE contents were comparable among the experimental diets (Table 1). Table 2 shows the AA composition of the BSF meal and the experimental diets. Leucine, valine and tyrosine were the most represented essential AA (EAA). Excepted for histidine, methionine and tyrosine, all EAA decreased with the increase of BSF inclusion. However, all diets covered the fish AA requirements. As far as the FA composition is concerned (Table 3), the concentration of total SFA increased at the increase of the insect meal in the diet. In particular, C12:0 showed a 42-fold higher concentration in BSF15 than in BSF0. Noticeable decreases were observed for total PUFA. Omega-3 FA drastically decreased and reached the absolute lowest concentration in the BSF15 diet.

\section{Growth performance}

The mortality ranged from 0 (BSF0 and BSF12) to $2.1 \%$ (BSF15) and was not affected by the dietary treatment (Table 4). No differences were observed for the considered growth performance traits $(P>0.05)$.

\section{Somatic indexes, carcass yield and coefficient of fatness}

The results concerning the somatic indexes, carcass yield and coefficient of fatness are reported in Table 5. The HSI showed an increasing trend with the increase of BSF meal inclusion in the diet. Specifically, HSI values were higher in BSF15 fish than BSF0 and BSF3 fish, while the other treatments showed intermediate values $(P<0.001)$. A similar trend was also observed for VSI, except for BSF0 that showed comparable values as BSF6, BSF9 and BSF12 $(P<0.01)$.

\section{Physical characteristics, proximate composition and fatty acid profile of fillets}

The dietary treatment did not affect either color or $\mathrm{pH}_{24}$ of the fillets (Table 6). The fillet's physical characteristics were also unaffected by diet (Table 7). 
Table 4 Effect of the dietary inclusion of BSF meal on growth performance of rainbow trout $(n=4)$

\begin{tabular}{lllllllll}
\hline & BSF0 & BSF3 & BSF6 & BSF9 & BSF12 & BSF15 & SEM & $P$-value \\
\hline Mortality, \% & 0.00 & 1.04 & 1.04 & 1.04 & 0.00 & 2.08 & 0.512 & 0.708 \\
ilBW, g & 100.1 & 100.1 & 100.4 & 100.0 & 100.4 & 100.0 & 0.388 & 0.999 \\
iFBW, g & 278.8 & 282.3 & 284.9 & 278.4 & 272.9 & 267.0 & 2.06 & 0.179 \\
iWG, g & 178.8 & 182.3 & 184.6 & 178.5 & 172.6 & 167.3 & 3.536 & 0.818 \\
SGR, \%/d & 0.84 & 0.84 & 0.84 & 0.83 & 0.82 & 0.78 & 0.010 & 0.675 \\
FCR & 1.08 & 1.09 & 1.09 & 1.12 & 1.13 & 1.18 & 0.013 & 0.398 \\
PER & 2.02 & 1.99 & 2.00 & 1.94 & 1.94 & 1.83 & 0.024 & 0.339 \\
\hline
\end{tabular}

Abbreviations: BSF Hermetia illucens, SEM standard error of the mean, ilBW individual initial body weight, iFBW individual final body weight, iWG individual weight gain, SGR specific growth rate, FCR feed conversion ratio, $P E R$ protein efficiency ratio

The DM, CP and EE contents of the fillets did not show differences among the dietary treatments. The ash content was higher in BSF0 compared to BSF9, BSF12 and BSF15, while the fish fed with BSF3 and BSF6 showed intermediate values.

As for FA contents, total SFA and total MUFA showed a clear increasing trend, while a decreasing trend was observed for total PUFA, as the level of BSF larva meal increased in the diet (Table 8). Consequently, the $\Sigma$ PUFA / $\Sigma$ SFA ratio of the fillets progressively decreased, ranking in the following order: $\mathrm{BSF} 0=\mathrm{BSF} 3=\mathrm{BSF} 6>$ BSF9 > BSF12 > BSF15. The fish fed with BSF15 showed a higher content of total SFA when compared to the fish fed with BSF0 (+29\%), while the fish fed with the other treatments showed intermediate values $(P<0.05)$. Regarding individual SFA, C12:0 was about 19-fold higher in BSF15 when compared to BSF0 (1.73 vs. $0.09 \mathrm{~g} / 100 \mathrm{~g}$ TFA, respectively; $P<0.001)$. An increasing trend was also observed for C14:0 with the dietary increase of the insect meal, while other individual SFA (i.e., C16:0, C17: 0, C18:0 and C20:0) only showed higher values in BSF15 when compared to the other treatments. Various branched chain fatty acids (BCFA) were detected. The rates of all of them, with the exception of $\mathrm{C} 18$ iso, were significantly affected by the diet. The majority of BCFA showed the absolute highest content when the fish were fed the BSF15 diet. Total MUFA and C18:1 c-9 were about 1.3-fold higher in BSF15 when compared to BSF0. As previously described for individual SFA and BCFA, some individual MUFA (i.e., C14:1 c-9 - which coeluted with $\mathrm{C} 15: 0$ in the chromatograms -, total C18:1 $t$ and C18:1 c-11) showed higher values in BSF15 when compared to the other treatments. The observed decrease of total PUFA was substantial (-58\% in BSF15 when compared to BSF0) and regarded both total n-3 and total n-6 FA $(P<0.001)$. The decrease was more marked for FA belonging to the $n-3$ ( $-81 \%$ considering total $n-3$ FA) than the n-6 (-43\% considering total n-6 FA) series. Consequently, the $\Sigma \mathrm{n}-3 / \sum \mathrm{n}-6$ FA ratio also significantly decreased while increasing BSF meal in the diet, following the order BSF0 $>$ BSF3 = BSF6 = BSF9 $>$ BSF12 > BSF15. All individual n6 FA showed significantly lower values in BSF15 when compared to the other treatments. Similar results were obtained for $\mathrm{C} 18: 3$ $n-3$ and C20:3 n-3, while the decreasing trend was gradual for long-chain n-3 PUFA (C20:5 n-3, C22:5 n-3 and C22:6 n-3).

\section{Morphometric investigation}

No differences were found for morphometry at the anterior gut, whereas villi were higher in the posterior gut of BSF6 and BSF9 groups when compared to BSF3 (Table 9).

Regarding the histopathological alterations of liver, absent to mild multifocal lymphoplasmacytic inflammatory infiltrates were observed with absent/mild vacuolar degeneration (Table 10). The anterior and posterior gut showed from absent to mild mucosal lymphoplasmacytic infiltration. However, BSF meal inclusion did not affect the severity of the observed histopathological alterations $(P>0.05)$.

Table 5 Effect of the dietary inclusion of BSF meal on somatic indexes, carcass yield and coefficient of fatness of rainbow trout $(n=28)$

\begin{tabular}{lllllllll}
\hline & BSF0 & BSF3 & BSF6 & BSF9 & BSF12 & BSF15 & SEM & $P$-value \\
\hline HSI & $1.20^{\mathrm{b}}$ & $1.22^{\mathrm{b}}$ & $1.37^{\mathrm{ab}}$ & $1.37^{\mathrm{ab}}$ & $1.39^{\mathrm{ab}}$ & $1.47^{\mathrm{a}}$ & 0.019 & 0.000 \\
VSI & $11.2^{\mathrm{ab}}$ & $11.0^{\mathrm{b}}$ & $11.6^{\mathrm{ab}}$ & $12.1^{\mathrm{ab}}$ & $12.3^{\mathrm{ab}}$ & $12.6^{\mathrm{ab}}$ & 0.143 & 0.008 \\
$\mathrm{CY}$ & 87.9 & 87.7 & 87.7 & 87.0 & 86.8 & 89.1 & 0.341 & 0.448 \\
$\mathrm{CF}$ & 3.65 & 3.64 & 3.64 & 3.82 & 3.84 & 3.24 & 0.093 & 0.622 \\
\hline
\end{tabular}

Abbreviations: BSF Hermetia illucens, SEM standard error of the mean, HSI hepatosomatic index, VSI viscerosomatic index, $C Y$ carcass yield, $C F$ coefficient of fatness. Different superscripts within a row indicate significant differences $(P<0.05)$ 
Table 6 Effect of the dietary inclusion of BSF meal on flesh color and $\mathrm{pH}_{24}$ of cranial, medial and caudal regions of rainbow trout fillets $(n=9)$

\begin{tabular}{|c|c|c|c|c|c|c|c|c|}
\hline & BSF0 & BSF3 & BSF6 & BSF9 & BSF12 & BSF15 & SEM & $P$-value \\
\hline \multicolumn{9}{|c|}{ Cranial region } \\
\hline$L^{*}$ & 42.3 & 46.1 & 43.5 & 45.0 & 43.2 & 43.4 & 0.799 & 0.788 \\
\hline$a^{*}$ & 0.35 & 0.42 & -0.32 & 2.06 & -0.35 & 0.33 & 0.255 & 0.069 \\
\hline$b^{*}$ & 6.25 & 8.06 & 6.32 & 8.17 & 6.17 & 6.60 & 0.258 & 0.051 \\
\hline $\mathrm{pH}_{24}$ & 6.49 & 6.31 & 6.38 & 6.32 & 6.37 & 6.42 & 0.020 & 0.101 \\
\hline \multicolumn{9}{|c|}{ Medial region } \\
\hline$L^{*}$ & 42.0 & 45.1 & 44.3 & 47.2 & 43.6 & 45.0 & 0.778 & 0.562 \\
\hline$a^{*}$ & 1.57 & 3.73 & 1.58 & 2.70 & 2.88 & 1.87 & 0.316 & 0.292 \\
\hline$b^{*}$ & 7.93 & 9.66 & 8.26 & 9.86 & 7.60 & 8.51 & 0.314 & 0.204 \\
\hline $\mathrm{pH}_{24}$ & 6.40 & 6.26 & 6.33 & 6.28 & 6.31 & 6.35 & 0.019 & 0.119 \\
\hline \multicolumn{9}{|c|}{ Caudal region } \\
\hline$L^{*}$ & 44.3 & 49.6 & 47.1 & 47.0 & 45.8 & 47.3 & 0.743 & 0.490 \\
\hline$a^{*}$ & 2.95 & 2.14 & 2.93 & 3.92 & 4.81 & 2.31 & 0.579 & 0.784 \\
\hline$b^{*}$ & 9.08 & 10.30 & 9.68 & 10.54 & 7.98 & 8.60 & 0.337 & 0.203 \\
\hline $\mathrm{pH}_{24}$ & 6.37 & 6.26 & 6.29 & 6.25 & 6.28 & 6.34 & 0.017 & 0.143 \\
\hline
\end{tabular}

Abbreviations: BSF Hermetia illucens, $L^{*}$ lightness, $a^{*}$ redness, $b^{*}$ yellowness, SEM standard error of the mean

\section{Digestibility trial}

The apparent digestibility of DM, CP, EE and GE was not influenced by diet $(P>0.05)$ (Table 11$)$. The ADC of DM ranged between $86.8 \%$ (BSF6) and $87.7 \%$ (BSF9). Overall, the ADC of CP and EE were higher than 94\% and $98 \%$, respectively. Results concerning $\mathrm{ADC}$ of $\mathrm{GE}$ ranged between 92.1\% (BSF9) and 93.1\% (BSF15).

\section{Discussion}

\section{Growth performance}

Starting from the first day of trial, all the fish promptly accepted all the experimental diets. After 131 days of trial, there were no significant differences among the groups in terms of growth performance and feed utilization. The results obtained in the present study showed that, in current typical commercial diets for trout, it is possible to substitute up to the $50 \%$ of FM with a partially defatted BSF larva meal (corresponding to a maximum of $15 \%$ dietary inclusion level) without adverse effects on the fish growth performance. Such results are consistent with previous trials in which other fish species were fed diets with inclusion levels up to
$20 \%$ of full-fat [33], partially defatted [21, 34] and highly defatted BSF meals $[19,35]$. Indeed, inclusion levels of BSF meal higher than 20\% can induce a stress response in rainbow trout [36]. Published studies show that dietary inclusion levels of about $33 \%$ and $26 \%$ of full-fat BSF meals [16, 37] or of a partially defatted BSF meal [15] determined a worsening of the WG and feed utilization. Similar results were also observed in meagre (Argyrosomus regius) when fed increasing amounts of a partially defatted BSF meal [20]. However, other trials showed that it could be possible to include up to $40 \%$ of a partially defatted BSF larva meal [14] or up to $50 \%$ of a full-fat BSF prepupae meal [13] in substitution of FM, without negative effects on the growth performance of adult and juvenile rainbow trout, respectively.

\section{Somatic indexes, carcass yield and coefficient of fatness} In literature, HSI values between $1 \%$ and $2 \%$ (as obtained in the current trial) are indicators of proper liver function [38]. Published data on the effect of insect meals on HSI values in rainbow trout are inconsistent. Similarly to what obtained in our trial, Dumas et al. [15] and

Table 7 Effect of the dietary inclusion of BSF meal on the physical characteristics of rainbow trout fillets $(n=9)$

\begin{tabular}{lllllllll}
\hline & BSF0 & BSF3 & BSF6 & BSF9 & BSF12 & BSF15 & SEM & P-value \\
\hline Drip loss, \% & 2.89 & 3.32 & 2.76 & 3.22 & 2.80 & 3.04 & 0.114 & 0.658 \\
Thawed loss, \% & 9.50 & 9.47 & 8.98 & 10.52 & 10.18 & 9.35 & 0.240 & 0.470 \\
Cooking loss, \% & 16.6 & 17.6 & 16.6 & 18.8 & 18.3 & 17.7 & 0.373 & 0.439 \\
Shear force, N & 28.8 & 26.0 & 21.1 & 25.8 & 26.7 & 22.71 & 1.142 & 0.434 \\
\hline
\end{tabular}

Abbreviations: BSF Hermetia illucens, SEM standard error of the mean 
Table 8 Effect of the dietary inclusion of BSF meal on fillet proximate composition $(\mathrm{g} / 100 \mathrm{~g} \mathrm{ww}$ ) and fatty acid profile ( $\mathrm{g} / 100 \mathrm{~g}$ of TFA) of rainbow trout $(n=9)$

\begin{tabular}{|c|c|c|c|c|c|c|c|c|}
\hline & BSF0 & BSF3 & BSF6 & BSF9 & BSF12 & BSF15 & SEM & $P$-value \\
\hline \multicolumn{9}{|l|}{ Proximate composition } \\
\hline DM & 25.8 & 26.8 & 27.2 & 25.5 & 26.1 & 26.6 & 0.303 & 0.643 \\
\hline $\mathrm{CP}$ & 19.2 & 20.0 & 18.3 & 19.2 & 19.6 & 20.5 & 0.323 & 0.493 \\
\hline $\mathrm{EE}$ & 4.44 & 4.97 & 5.34 & 4.74 & 5.13 & 4.76 & 0.223 & 0.897 \\
\hline Ash & $2.06^{\mathrm{a}}$ & $1.68^{\mathrm{ab}}$ & $1.54^{\mathrm{ab}}$ & $1.43^{b}$ & $1.28^{\mathrm{b}}$ & $1.22^{\mathrm{b}}$ & 0.065 & 0.010 \\
\hline \multicolumn{9}{|l|}{ Fatty acid composition } \\
\hline $\mathrm{C} 12: 0$ & $0.09^{e}$ & $0.28^{\mathrm{de}}$ & $0.44^{d}$ & $0.75^{c}$ & $1.16^{\mathrm{b}}$ & $1.73^{\mathrm{a}}$ & 0.081 & 0.000 \\
\hline $\mathrm{C} 13$ iso & $0.07^{\mathrm{ab}}$ & $0.07^{\mathrm{ab}}$ & $0.06^{\mathrm{ab}}$ & $0.07^{\mathrm{a}}$ & $0.05^{\mathrm{ab}}$ & $0.04^{\mathrm{b}}$ & 0.003 & 0.024 \\
\hline C14:0 & $2.93^{\mathrm{C}}$ & $3.00^{b c}$ & $2.91^{\mathrm{c}}$ & $3.16^{b c}$ & $3.35^{\mathrm{b}}$ & $4.36^{\mathrm{a}}$ & 0.078 & 0.000 \\
\hline C15 iso & $0.07^{\mathrm{b}}$ & $0.07^{b}$ & $0.07^{b}$ & $0.06^{b}$ & $0.07^{\mathrm{b}}$ & $0.09^{\mathrm{a}}$ & 0.001 & 0.000 \\
\hline C15 aiso & $0.02^{\mathrm{b}}$ & $0.02^{\mathrm{b}}$ & $0.02^{b}$ & $0.02^{b}$ & $0.03^{\mathrm{ab}}$ & $0.04^{\mathrm{a}}$ & 0.002 & 0.000 \\
\hline C14:1 c-9+C15:0 & $0.33^{\mathrm{b}}$ & $0.33^{b}$ & $0.32^{b}$ & $0.34^{b}$ & $0.34^{b}$ & $0.43^{\mathrm{a}}$ & 0.007 & 0.000 \\
\hline C16:0 & $18.6^{\mathrm{b}}$ & $19.1^{b}$ & $18.8^{b}$ & $19.6^{\mathrm{b}}$ & $20.2^{b}$ & $25.4^{\mathrm{a}}$ & 0.361 & 0.000 \\
\hline $\mathrm{C} 17$ iso & $0.21^{\mathrm{b}}$ & $0.22^{\mathrm{b}}$ & $0.21^{\mathrm{b}}$ & $0.20^{\mathrm{b}}$ & $0.22^{b}$ & $0.28^{\mathrm{a}}$ & 0.005 & 0.000 \\
\hline C17 aiso & $0.43^{c d}$ & $0.42^{d}$ & $0.42^{d}$ & $0.50^{b c}$ & $0.52^{b}$ & $0.64^{\mathrm{a}}$ & 0.013 & 0.000 \\
\hline C16:1 c-9 & $4.88^{\mathrm{C}}$ & $5.14^{\mathrm{bc}}$ & $5.03^{b c}$ & $5.29^{\mathrm{bc}}$ & $5.52^{b}$ & $6.31^{\mathrm{a}}$ & 0.085 & 0.000 \\
\hline $\mathrm{C} 17: 0$ & $0.29^{b}$ & $0.28^{b}$ & $0.29^{b}$ & $0.27^{b}$ & $0.28^{b}$ & $0.40^{\mathrm{a}}$ & 0.008 & 0.000 \\
\hline $\mathrm{C} 18$ iso & 0.12 & 0.11 & 0.10 & 0.12 & 0.12 & 0.12 & 0.004 & 0.421 \\
\hline$C 17: 1$ c-9 & 0.19 & 0.18 & 0.20 & 0.23 & 0.21 & 0.21 & 0.006 & 0.217 \\
\hline C18:0 & $5.11^{\mathrm{b}}$ & $5.13^{b}$ & $5.10^{\mathrm{b}}$ & $5.32^{b}$ & $5.44^{b}$ & $6.53^{\mathrm{a}}$ & 0.078 & 0.000 \\
\hline C18:1 t-6-10 & $0.09^{b}$ & $0.10^{\mathrm{b}}$ & $0.09^{b}$ & $0.10^{\mathrm{b}}$ & $0.11^{\mathrm{ab}}$ & $0.12^{\mathrm{a}}$ & 0.002 & 0.000 \\
\hline C18:1 t-11-12 & 0.03 & 0.03 & 0.02 & 0.02 & 0.02 & 0.03 & 0.001 & 0.104 \\
\hline C18:1 t-13-14 + c-6-8 & $0.12^{\mathrm{b}}$ & $0.12^{b}$ & $0.11^{\mathrm{b}}$ & $0.13^{b}$ & $0.12^{\mathrm{b}}$ & $0.16^{\mathrm{a}}$ & 0.003 & 0.000 \\
\hline C18:1 c-9 & $23.3^{d}$ & $24.0^{c d}$ & $24.9^{\mathrm{bcd}}$ & $25.4^{b c}$ & $26.6^{\mathrm{b}}$ & $31.3^{\mathrm{a}}$ & 0.397 & 0.000 \\
\hline C18:1 c-11 & $2.88^{\mathrm{b}}$ & $2.93^{b}$ & $2.92^{b}$ & $2.93^{b}$ & $2.99^{b}$ & $3.50^{\mathrm{a}}$ & 0.038 & 0.000 \\
\hline C18:2 n-6 & $21.0^{\mathrm{a}}$ & $21.6^{a}$ & $21.8^{\mathrm{a}}$ & $20.9^{a}$ & $20.7^{a}$ & $12.3^{b}$ & 0.513 & 0.000 \\
\hline C18:3 n-3 & $2.51^{\mathrm{a}}$ & $2.62^{\mathrm{a}}$ & $2.51^{\mathrm{a}}$ & $2.41^{\mathrm{a}}$ & $2.22^{\mathrm{a}}$ & $0.93^{b}$ & 0.089 & 0.000 \\
\hline C18:3 n-6 & $0.32^{\mathrm{a}}$ & $0.31^{\mathrm{a}}$ & $0.34^{\mathrm{a}}$ & $0.36^{\mathrm{a}}$ & $0.29^{\mathrm{a}}$ & $0.12^{b}$ & 0.014 & 0.000 \\
\hline C20:0 & $0.16^{\mathrm{b}}$ & $0.17^{b}$ & $0.18^{b}$ & $0.18^{b}$ & $0.18^{b}$ & $0.23^{a}$ & 0.004 & 0.000 \\
\hline C20:1 c-9 & $1.17^{\mathrm{b}}$ & $1.15^{\mathrm{b}}$ & $1.20^{b}$ & $1.22^{b}$ & $1.26^{\mathrm{ab}}$ & $1.44^{\mathrm{a}}$ & 0.024 & 0.003 \\
\hline$C 20: 1$ c-11 & $0.17^{\mathrm{a}}$ & $0.16^{\mathrm{ab}}$ & $0.15^{\mathrm{ab}}$ & $0.15^{a b}$ & $0.14^{b}$ & $0.05^{c}$ & 0.006 & 0.000 \\
\hline$C 20: 2$ n-6 & $0.98^{\mathrm{a}}$ & $0.93^{\mathrm{a}}$ & $1.01^{\mathrm{a}}$ & $0.96^{\mathrm{a}}$ & $0.95^{\mathrm{a}}$ & $0.66^{b}$ & 0.025 & 0.000 \\
\hline C20:3 n-3 & $0.15^{\mathrm{a}}$ & $0.15^{\mathrm{a}}$ & $0.16^{\mathrm{a}}$ & $0.14^{\mathrm{a}}$ & $0.14^{\mathrm{a}}$ & $0.07^{b}$ & 0.005 & 0.000 \\
\hline$C 20: 3 n-6$ & $0.63^{\mathrm{a}}$ & $0.59^{\mathrm{a}}$ & $0.64^{\mathrm{a}}$ & $0.70^{\mathrm{a}}$ & $0.60^{\mathrm{a}}$ & $0.20^{\mathrm{b}}$ & 0.025 & 0.000 \\
\hline C20:4 n-6 & $0.75^{a}$ & $0.72^{\mathrm{a}}$ & $0.73^{a}$ & $0.76^{\mathrm{a}}$ & $0.62^{\mathrm{a}}$ & $0.22^{b}$ & 0.031 & 0.000 \\
\hline$C 20: 5 n-3$ & $2.96^{\mathrm{ab}}$ & $3.14^{\mathrm{a}}$ & $2.68^{\mathrm{ab}}$ & $2.53^{b}$ & $1.82^{c}$ & $0.54^{d}$ & 0.128 & 0.000 \\
\hline C22:0 & 0.10 & 0.10 & 0.12 & 0.12 & 0.11 & 0.11 & 0.002 & 0.055 \\
\hline C22:1 n-9 & 0.14 & 0.14 & 0.15 & 0.16 & 0.17 & 0.17 & 0.006 & 0.517 \\
\hline$C 22: 5 n-3$ & $0.92^{\mathrm{ab}}$ & $1.03^{\mathrm{a}}$ & $0.92^{\mathrm{ab}}$ & $0.80^{\mathrm{b}}$ & $0.55^{c}$ & $0.12^{d}$ & 0.046 & 0.000 \\
\hline$C 22: 6$ n-3 & $8.19^{\mathrm{a}}$ & $5.56^{\mathrm{b}}$ & $5.35^{b c}$ & $4.18^{\mathrm{cd}}$ & $2.97^{d}$ & $1.11^{\mathrm{e}}$ & 0.326 & 0.000 \\
\hline$\Sigma$ SFA & $27.7^{b}$ & $28.4^{\mathrm{ab}}$ & $28.2^{\mathrm{ab}}$ & $29.7^{\mathrm{ab}}$ & $31.0^{\mathrm{ab}}$ & $35.7^{\mathrm{a}}$ & 0.821 & 0.043 \\
\hline$\Sigma$ BCFA & $0.91^{b c}$ & $0.91^{b c}$ & $0.86^{c}$ & $0.97^{b}$ & $1.00^{b}$ & $1.22^{\mathrm{a}}$ & 0.018 & 0.000 \\
\hline$\Sigma$ MUFA & $33.0^{\mathrm{d}}$ & $34.0^{c d}$ & $34.8^{\mathrm{bcd}}$ & $35.6^{b c}$ & $37.2^{b}$ & $43.3^{\mathrm{a}}$ & 0.519 & 0.000 \\
\hline
\end{tabular}


Table 8 Effect of the dietary inclusion of BSF meal on fillet proximate composition $(\mathrm{g} / 100 \mathrm{~g} \mathrm{ww})$ and fatty acid profile (g/100 $\mathrm{g}$ of TFA) of rainbow trout $(n=9)$ (Continued)

\begin{tabular}{|c|c|c|c|c|c|c|c|c|}
\hline & BSF0 & BSF3 & BSF6 & BSF9 & BSF12 & BSF15 & SEM & $P$-value \\
\hline$\Sigma$ PUFA & $38.4^{a}$ & $36.7^{\mathrm{ab}}$ & $36.1^{\mathrm{ab}}$ & $33.8^{\mathrm{bc}}$ & $30.8^{c}$ & $16.3^{d}$ & 1.089 & 0.000 \\
\hline$\Sigma$ PUFA / $\Sigma$ SFA & $1.39^{\mathrm{a}}$ & $1.29^{\mathrm{a}}$ & $1.28^{\mathrm{a}}$ & $1.14^{\mathrm{b}}$ & $1.00^{c}$ & $0.39^{d}$ & 0.047 & 0.000 \\
\hline$\sum n-3$ & $14.7^{\mathrm{a}}$ & $12.5^{\mathrm{b}}$ & $11.6^{\mathrm{bc}}$ & $10.1^{c}$ & $7.71^{d}$ & $2.78^{e}$ & 0.559 & 0.000 \\
\hline$\sum n-6$ & $23.7^{\mathrm{a}}$ & $24.2^{\mathrm{a}}$ & $24.5^{\mathrm{a}}$ & $23.7^{\mathrm{a}}$ & $23.1^{\mathrm{a}}$ & $13.5^{b}$ & 0.590 & 0.000 \\
\hline$\Sigma n-3 / \Sigma n-6$ & $0.62^{\mathrm{a}}$ & $0.51^{\mathrm{b}}$ & $0.47^{\mathrm{b}}$ & $0.43^{\mathrm{b}}$ & $0.34^{c}$ & $0.19^{d}$ & 0.020 & 0.000 \\
\hline
\end{tabular}

Abbreviations: BSF Hermetia illucens, $w w$ wet weight, TFA total fatty acid, SEM standard error of the mean, DM dry matter, CP crude protein, EE ether extract, $C$ cis, $t$ trans, SFA saturated fatty acids, BCFA branched chain fatty acids, MUFA monounsaturated fatty acids, PUFA polyunsaturated fatty acids. Values are reported as mean of duplicate analyses. Different superscripts within a row indicate significant differences $(P<0.05)$

Chemello et al. [22] also reported an increase of HSI in rainbow trout fed with partially defatted BSF and Tenebrio molitor meals, respectively. On the contrary, Sealey et al. [37] recorded a decrease in HSI in fish fed with diets characterized by increasing levels of BSF meal. Renna et al. [14] observed that inclusion levels up to $40 \%$ of a partially defatted BSF larva meal did not influence the HSI in rainbow trout. The dissimilarity of results found in literature could be related to several factors, such as the insect species and the nutritional composition of the insect meal, whereas the chemical composition of BSF meal, especially its fat content and FA profile, could be influenced by the rearing substrate of the larva $[9,39,40]$ and the defatting method [15, 41]. In addition, results can also differ due to fish species, size and physiological status.

\section{Physical characteristics, proximate composition and fatty acid profile of fillets}

The $\mathrm{pH}$ of fish fillets provides a measure of the stress status of the fish and the flesh freshness. Changes in $\mathrm{pH}$ could be due by multiple factors, such as high density in tank, stress in pre-killing phase and dietary treatments [42]. An increase of the $\mathrm{pH}$ during storage could also reflect the production of bacterial metabolites and therefore a decrease of the shelf life of the product [43]. In the currently trial, the $\mathrm{pH}$ of the fillets was not affected by diet, and the recorded values are in line with those previously reported for rainbow trout fed with BSF larva meals [14, 44] and Tenebrio molitor larva meals [38]. The results obtained in our study also showed that an inclusion of partially defatted BSF meal up to $15 \%$ did not influence the color of the raw fillets. Such results confirm those recently obtained by Secci et al. [44] in rainbow trout fed up to $40 \%$ of partially defatted BSF larva meal. The lack of influence of BSF meal on fillet color should be considered as an advantage. In fact, color is an important quality parameter of the fillet, as it directly influences the perception of freshness, being also used by consumers to evaluate product quality [45].

We observed no differences in terms of fillets DL, TL, $\mathrm{CL}$ and SF among the experimental groups. Similarly, Secci et al. [44] and Borgogno et al. [46] reported no significant variations for the SF and CL when rainbow trout were fed with BSF meals. In our trial, both SF and CL showed higher values when compared to those obtained by the above-mentioned authors. Such difference may be due to different factors, such as sampling procedure, preservation and storage of samples and analytical methods used.

The lack of effects of BSF meal on fillet DM, CP and EE contents confirms previous findings obtained by Renna et al. [14], Mancini et al. [47] and Reyes et al. [48], when BSF larva meals were included in rainbow trout diets up to inclusion levels of $25 \%$. In our trial, the ash content of the fillets showed a decreasing trend following increasing levels of BSF larva meal inclusion in the diet. When compared to FM, BSF meal showed noticeably lower phosphorous levels [49]. Such difference may have determined the observed significant decreases in fillet ash content at increasing BSF levels in the diet. However, in young grass carp (Ctenopharyngodon idella Valenciennes), Wen et al. [50] observed decreased levels of ash in fillets while increasing the dietary level of available phosphorous. As no information can be found in literature on rainbow trout, further studies are needed to clearly understand the obtained results.

Fish contain high amounts of long-chain n-3 PUFA, well known to exert beneficial effects on human health [51]. Usually, the FA composition of fish fillets reflects

Table 9 Effect of the dietary inclusion of BSF meal on morphometric traits of anterior and posterior gut of rainbow trout ( $n=8$ )

\begin{tabular}{|c|c|c|c|c|c|c|c|c|}
\hline & BSF0 & BSF3 & BSF6 & BSF9 & BSF12 & BSF15 & SEM & $P$-value \\
\hline Vh anterior gut & 0.54 & 0.51 & 0.54 & 0.50 & 0.54 & 0.49 & 0.015 & 0.906 \\
\hline Vh posterior gut & $0.66^{a b c}$ & $0.53^{c}$ & $0.66^{a}$ & $0.63^{\mathrm{ab}}$ & $0.63^{a b c}$ & $0.53^{\mathrm{bc}}$ & 0.013 & 0.007 \\
\hline
\end{tabular}

Abbreviations: BSF Hermetia illucens, SEM standard error mean, Vh villus height. Different superscripts within a row indicate significant differences $(P<0.05)$ 
Table 10 Effect of the dietary inclusion of BSF meal on histopathological alterations of liver and gut of rainbow trout ( $n=8$ )

\begin{tabular}{|c|c|c|c|c|c|c|c|}
\hline & BSF0 & BSF3 & BSF6 & BSF9 & BSF12 & BSF15 & $P$-value \\
\hline \multicolumn{8}{|l|}{ Liver } \\
\hline Inflammation, median (IR) & $\begin{array}{l}0.5 \\
(0.0-1.0)\end{array}$ & $\begin{array}{l}0.0 \\
(0.0-0.4)\end{array}$ & $\begin{array}{l}0.0 \\
(0.0-0.0)\end{array}$ & $\begin{array}{l}0.0 \\
(0.0-1.0)\end{array}$ & $\begin{array}{l}0.0 \\
(0.0-0.0)\end{array}$ & $\begin{array}{l}0.0 \\
(0.0-0.0)\end{array}$ & 0.057 \\
\hline Degeneration, median (IR) & $\begin{array}{l}0.0 \\
(0.0-0.4)\end{array}$ & $\begin{array}{l}0.0 \\
(0.0-0.5)\end{array}$ & $\begin{array}{l}0.25 \\
(0.0-1.0)\end{array}$ & $\begin{array}{l}1.25 \\
(0.5-1.9)\end{array}$ & $\begin{array}{l}0.25 \\
(0.0-1.0)\end{array}$ & $\begin{array}{l}0.0 \\
(0.0-1.0)\end{array}$ & 0.071 \\
\hline \multicolumn{8}{|l|}{ Gut } \\
\hline Anterior, median (IR) & $\begin{array}{l}0.0 \\
(0.0-0.0)\end{array}$ & $\begin{array}{l}0.0 \\
(0.0-0.5)\end{array}$ & $\begin{array}{l}0.0 \\
(0.0-0.9)\end{array}$ & $\begin{array}{l}0.0 \\
(0.0-0.0)\end{array}$ & $\begin{array}{l}0.0 \\
(0.0-0.8)\end{array}$ & $\begin{array}{l}0.0 \\
(0.0-0.0)\end{array}$ & 0.180 \\
\hline Posterior, median (IR) & $\begin{array}{l}0.0 \\
(0.0-0.8)\end{array}$ & $\begin{array}{l}0.0 \\
(0.0-0.0)\end{array}$ & $\begin{array}{l}0.0 \\
(0.0-0.0)\end{array}$ & $\begin{array}{l}0.0 \\
(0.0-0.0)\end{array}$ & $\begin{array}{l}0.0 \\
(0.0-0.0)\end{array}$ & $\begin{array}{l}0.0 \\
(0.0-0.0)\end{array}$ & 0.345 \\
\hline
\end{tabular}

Abbreviations: BSF Hermetia illucens, IR interquartile range

that of the administered diet [14]. The FA content and composition of insect larvae (and derived meals) depend on the considered insect species, rearing substrate, developmental stage and processing (e.g., defatting methods) [52]. Differently from FM, insects are generally rich in SFA and poor in PUFA [53]. In particular, BSF larval fat consists mainly of C12:0 and other SFA $[9,52]$, as confirmed by the analyses of the tested BSF meal. Even if the BSF meal used in this trial was partially defatted (EE: 7.0 $\mathrm{g} / 100 \mathrm{~g}$ as fed), this led to a noticeable increase of C12:0 in the BSF-containing diets when compared to the FMcontrol diet (BSF0), as already observed by other authors $[14,20]$. In recent trials where high inclusion levels of insect meals were evaluated in aquafeed for various fish species, significant alterations of the FA composition of fish whole body and fish fillets were observed [21, 47, 54]. The most frequently reported modifications were increasing levels of SFA associated with reductions of PUFA contents, particularly when considering long-chain PUFA of the n-3 series (i.e., C20:5n-3 and C22:6n-3), which also led to undesirable decreases of the PUFA/SFA and $n-3 / n-6$ PUFA ratios of the product $[19,20,44]$. Our results confirm such findings and, in addition, clearly show that the FA composition of trout fillets could be negatively affected even in case of low inclusion levels of BSF meal as a replacement of FM in typical commercial diets.

\section{Morphometric investigation}

Regardless the dietary treatment, Vh showed a proximodistal increasing gradient from anterior to posterior gut.
In literature, the majority of the studies conducted in mammals and poultry reported a proximo-distal decreasing gradient from anterior to posterior gut [55]. This is due to the different intensity of nutrient digestion and absorption processes along the gut. Only few publications are available on the morphometry of rainbow trout and they mainly concentrated on the anterior gut [56] as it is the most important site for nutrient absorption, receiving physical, chemical and hormonal stimuli caused by the presence of the diet in the lumen $[57,58]$. The lack of differences for $\mathrm{Vh}$ in the anterior gut among the dietary treatments is a positive finding and it is in accordance with Renna et al. [14] who did not record any morphological changes in the intestine of trout fed up to $40 \%$ of BSF meal. Moreover, the unaffected morphometry of the anterior gut could also explain the unchanged growth performances and diet digestibility recorded for the trout of the present study, suggesting good nutrient absorption and utilization with BSF meal dietary inclusion levels up to $15 \%$. On the contrary, BSF meal influenced $\mathrm{Vh}$ in the posterior gut, being lower in BSF3 diet compared to the other treatments. This is one of the first studies describing posterior gut in trout and further study are needed to better investigate this upward trend. Regarding the histopathological alterations of liver and gut, they varied from absent to mild in all the organs. The absence of adverse effects related to dietary BSF meal inclusion observed in liver and gut of the present study is in agreement with published literature $[36,59,60]$.

Table 11 Apparent digestibility coefficients (ADC) of the experimental diets $(n=4)$

\begin{tabular}{lllllllll}
\hline & BSF0 & BSF3 & BSF6 & BSF9 & BSF12 & BSF15 & SEM & P-value \\
\hline $\mathrm{ADC}_{\mathrm{DM},}, \%$ & 87.3 & 87.1 & 86.8 & 87.7 & 86.9 & 87.5 & 0.332 & 0.988 \\
$\mathrm{ADC}_{\mathrm{CP},} \%$ & 94.7 & 94.2 & 94.4 & 94.6 & 94.2 & 94.6 & 0.163 & 0.967 \\
$\mathrm{ADC}_{\mathrm{EE},} \%$ & 98.8 & 98.7 & 98.7 & 98.8 & 98.6 & 98.6 & 0.054 \\
$\mathrm{ADC}_{\mathrm{GE},} \%$ & 92.9 & 92.5 & 92.7 & 92.1 & 92.6 & 93.4 & 0.240 & 0.903 \\
\hline
\end{tabular}

Abbreviations: BSF Hermetia illucens, SEM standard error of the mean, DM dry matter, $C P$ crude protein, $E E$ ether extract, GE gross energy. Different superscript letters within a row indicate significant differences $(P<0.05)$ 


\section{Digestibility trial}

The ADC values of nutrients and energy were high and comparable among the experimental groups. Such results suggest that BSF larva meal is well digested by rainbow trout and its inclusion up to $15 \%$ in the diet does not adversely affect the fish growth performance. In fact, studies conducted on rainbow trout with BSF larva meal [14] and Tenebrio molitor larva meal [22, 61], showed that dietary inclusion levels up to $25 \%$ did not affect the apparent digestibility of nutrients and energy.

\section{Conclusions}

The findings of this study suggest that partially defatted black soldier fly larva meal can be considered a suitable ingredient in low fishmeal-based diets for rainbow trout. In this study, we did not observe any adverse effect on growth performance, somatic indexes, fillet physical quality parameters and chemical composition, and diets digestibility. However, the FA composition of fillets worsened while increasing the level of BSF meal in the diets. In particular, a decrease of PUFA, and an increase of total SFA and total MUFA was observed. The commercial use of insect meal for aquaculture feed is a good approach to reduce the environmental impact and support a sustainable increase in aquaculture production.

\section{Abbreviations}

ADC: Apparent digestibility coefficient; ADF: Acid detergent fiber; BCFA: Branched chain fatty acids; BSF: Hermetia illucens; c: cis; CF: Coefficient of fatness; CL: Cooking loss; CP: Crude protein; CY: Carcass yield; DL: Drip loss; DM: Dry matter; EE: Ether extract; FA: Fatty acid; FAME: Fatty acid methyl ester; FBW: Final body weight; FCR: Feed conversion ratio; FM: Fish meal; GE: Gross energy; HSI: Hepatosomatic index; IBW: Initial body weight; IR: Interquartile range; MUFA: Monounsaturated fatty acids; nd: Not detected; PAPs: Processed animal proteins; PER: Protein efficiency ratio;

PUFA: Polyunsaturated fatty acids; SEM: Standard error of the mean; SF: Shear force; SFA: Saturated fatty acids; SGR: Specific growth rate; $t$ : trans; TFA: Total fatty acids; TL: Thawed loss; Vh: Villus height; VSI: Viscerosomatic index; WG: Weight gain; ww: Wet weight

\section{Acknowledgments}

The authors would like to thank MUTATEC (Caumont-sur-Durance, France) for providing the black soldier fly meal.

\section{Authors' contributions}

CC, IB, AS and LG conceived and designed the experiment. CC, IB, GC, SBO, FG, AS, AT, MR and LG prepared the diets, performed the growth and digestibility trial and collected the experimental data. $A B$ and $C C$ performed the fillet physical quality parameters. CC, CL, VM and AT carried out the chemical analyses. MTC and EC performed the histomorphometric investigations and analysed the data. CC, $A B$, IB and MR performed the statistical analysis. CC, FG, MR and LG analysed and interpreted the data. CC, $M R$ and $L G$ wrote the first draft of the manuscript. All the authors critically reviewed the manuscript for its intellectual content and gave their approval for the final version to be published.

\section{Funding}

This research was funded by AGER project "Fine Feed for Fish (4F)", Rif. nr. 2016-01-01. Dr. Giulia Chemello was supported by a research grant of the University of Turin.
Availability of data and materials

The datasets analysed in the current study are available from the corresponding author on request.

\section{Declarations}

Ethics approval and consent to participate

The experimental protocol was approved by the Ethical Committee of the University of Turin (Italy) (protocol $n^{\circ} 143811$ ).

Consent for publication

Not applicable.

Competing interests

The authors declare that they have no competing interests.

\section{Author details}

${ }^{1}$ Department of Agricultural, Forest and Food Sciences, University of Turin, Largo P. Braccini 2, 10095 Grugliasco, TO, Italy. ${ }^{2}$ Department of Veterinary Sciences, University of Turin, Largo P. Braccini 2, 10095 Grugliasco, TO, Italy. ${ }^{3}$ Institute of Science of Food Production, National Research Council, Largo P. Braccini 2, 10095 Grugliasco, TO, Italy. ${ }^{4}$ Department of Comparative Biomedicine and Food Science, University of Padua, Viale dell'Università 16, 35020 Legnaro, PD, Italy.

Received: 29 November 2020 Accepted: 22 February 2021

Published online: 16 April 2021

\section{References}

1. Smárason BÖ, Alriksson B, Jóhannsson R. Safe and sustainable protein sources from the forest industry - the case of fish feed. Trends Food Sci Technol. 2019;84:12-4. https://doi.org/10.1016/j.tifs.2018.03.005.

2. FAO (Food and Agriculture Organization of the United Nation). The state of World Fisheries and Aquaculture 2020. Sustainability in action. Rome: Food and Agriculture Organization of the United Nations (FAO); 2020. https://doi. org/10.4060/ca9229en.

3. Engle RC, D'Abramo L, Ponniah AG, Slater M. Global Aquaculture 2050. J World Aquacult Soc. 2018:48(1):3-6. https://doi.org/10.1111/jwas.12400.

4. Olsen RL, Hasan MR. A limited supply of fishmeal: impact on future increases in global aquaculture production. Trends Food Sci Technol. 2012; 27(2):120-8. https://doi.org/10.1016/j.tifs.2012.06.003.

5. Vongvichith B, Morioka S, Sugita T, Phousavanh N, Phetsanghanh N, Chanthasone $\mathrm{P}$, et al. Evaluation of the efficacy of aquaculture feeds for the climbing perch Anabas testudineus: replacement of fishmeal by black soldier fly Hermetia illucens prepupae. Fish Sci. 2020;86(1):145-51. https://doi.org/1 0.1007/s12562-019-01381-5.

6. Smetana S, Schmitt E, Mathys A. Sustainable use of Hermetia illucens insect biomass for feed and food: Attributional and consequential life cycle assessment. Resour Conserv Recycl. 2019;144:285-96. https://doi.org/10.101 6/j.resconrec.2019.01.042.

7. Gasco L, Biancarosa I, Liland NS. From waste to feed: a review of recent knowledge on insects as producers of protein and fat for animal feeds. Curr Opin Green Sustain Chem. 2020;23:67-79. https://doi.org/10.1016/j.cogsc.2 020.03.003.

8. Meneguz M, Schiavone A, Gai F, Dama A, Lussiana C, Renna M, et al. Effect of rearing substrate on growth performance, waste reduction efficiency and chemical composition of black soldier fly (Hermetia illucens) larvae. J Sci Food Agric. 2018:98:5776-84. https://doi.org/10.1002/jsfa.9127.

9. Barragan-Fonseca KB, Dicke M, van Loon JJ. Nutritional value of the black soldier fly (Hermetia illucens L.) and its suitability as animal feed - a review. J Insects Food Feed. 2017;3(2):105-20. https://doi.org/10.3920/JIFF2016.0055.

10. Gasco L, Acuti G, Bani P, Dalle Zotte A, Danieli PP, De Angelis A, et al. Insect and fish by-products as sustainable alternatives to conventional animal proteins in animal nutrition. Ital J Anim Sci. 2020;19:360-72. https://doi.org/1 0.1080/1828051X.2020.1743209.

11. Kogut MH, Arsenault RJ. Editorial: gut health: the new paradigm in food animal production. Front Vet Sci. 2016;3:10-3. https://doi.org/10.3389/fvets.2 016.00071.

12. Cardinaletti G, Randazzo B, Messina M, Zarantoniello M, Giorgini E, Zimbelli A, et al. Effects of graded dietary inclusion level of full-fat Hermetia illucens 
prepupae meal in practical diets for rainbow trout (Oncorhynchus mykiss). Animals. 2019;9(5):251. https://doi.org/10.3390/ani9050251.

13. Renna M, Schiavone A, Gai F, Dabbou S, Lussiana C, Malfatto V, et al. Evaluation of the suitability of a partially defatted black soldier fly (Hermetia illucens L.) larvae meal as ingredient for rainbow trout (Oncorhynchus mykiss Walbaum) diets. J Anim Sci Biotechnol. 2017:8:57. https://doi.org/10.1186/s4 0104-017-0191-3.

14. Dumas A, Raggi T, Barkhouse J, Lewis E, Weltzien E. The oil fraction and partially defatted meal of black soldier fly larvae (Hermetia illucens) affect differently growth performance, feed efficiency, nutrient deposition, blood glucose and lipid digestibility of rainbow trout (Oncorhynchus mykiss). Aquaculture. 2018;492:24-34. https://doi.org/10.1 016/j.aquaculture.2018.03.038.

15. St-Hilaire S, Sheppard C, Tomberlin J, Irving S, Newton L, McGuire M, et al. Fly prepupae as a feedstuff for rainbow trout, Oncorhynchus mykiss. J World Aquacult Soc. 2007;38:59-67. https://doi.org/10.1111/j.1749-7345.2006.00073.x.

16. Zarantoniello M, Bruni L, Randazzo B, Vargas A, Gioacchini G, Truzzi C, et al. Partial dietary inclusion of Hermetia illucens (black soldier Fly) full-fat prepupae in zebrafish feed: biometric, histological, biochemical, and molecular implications. Zebrafish. 2018;15(5):519-32. https://doi.org/10.1089/ zeb.2018.1596

17. Józefiak A, Nogales-Mérida S, Mikołajczak Z, Rawski M, Kierończyk B, Mazurkiewicz J. The utilization of full-fat insect meal in rainbow trout (Oncorhynchus mykiss) nutrition: the effects on growth performance, intestinal microbiota and gastrointestinal tract histomorphology. Ann Anim Sci. 2019;19(3):747-65. https://doi.org/10.2478/aoas-2019-0020.

18. Caimi C, Renna M, Lussiana C, Bonaldo A, Gariglio M, Meneguz M, et al. First insights on black soldier Fly (Hermetia illucens L.) larvae meal dietary administration in Siberian sturgeon (Acipenser baerii Brandt) juveniles. Aquaculture. 2020;515:734539. https://doi.org/10.1016/j.aqua culture.2019.734539.

19. Guerreiro I, Castro C, Antunes B, Coutinho F, Rangel F, Couto A, et al. Catching black soldier fly for meagre: growth, whole-body fatty acid profile and metabolic responses. Aquaculture. 2020;516:734613. https://doi.org/10.1 016/j.aquaculture.2019.734613.

20. Stejskal V, Tran HQ, Prokesova M, Gebauer T, Giang PT, Gai F, et al. Partially defatted Hermetia illucens larva meal in diet of Eurasian perch (Perca fluviatilis) juveniles. Animals. 2020;10:1876. https://doi.org/10.33 90/ani10101876.

21. Chemello G, Renna M, Caimi C, Guerreiro I, Oliva-Teles A, Enes P, et al. Partially defatted Tenebrio molitor larva meal in diets for grow-out rainbow trout, Oncorhynchus mykiss (Walbaum): effects on growth performance, diet digestibility and metabolic responses. Animals. 2020;10(2):229. https://doi. org/10.3390/ani10020229.

22. AOAC International. Official methods of analysis of AOAC international. 16th ed. Gaithersburg: Association of Official Analytical Chemists; 2000.

23. AOAC International. Official methods of analysis of AOAC international. 17th ed. Gaithersburg: Association of Official Analytical Chemists; 2003.

24. Finke MD. Estimate of chitin in raw whole insects. Zoo Biol. 2007;26(2):10515. https://doi.org/10.1002/zoo.20123.

25. De Marco M, Martínez S, Hernandez F, Madrid J, Gai F, Rotolo L, et al. Nutritional value of two insect larval meals (Tenebrio molitor and Hermetia illucens) for broiler chickens: apparent nutrient digestibility, apparent ileal amino acid digestibility and apparent metabolisable energy. Anim Feed Sci Technol. 2015;209:211-8. https://doi.org/10.1016/j.anifeedsci.2015.08.006.

26. Dabbou S, Gasco L, Lussiana C, Brugiapaglia A, Biasato I, Renna M, et al. Yellow mealworm (Tenebrio molitor L.) larvae inclusion in diets for freerange chickens: effects on meat quality and fatty acid profile. Renew Agr Food Syst. 2020;35(5):571-8. https://doi.org/10.1017/S1742170519000206.

27. Dabbou S, Gai F, Renna M, Rotolo L, Dabbou S, Lussiana C, et al. Inclusion of bilberry pomace in rabbit diets: effects on carcass characteristics and meat quality. Meat Sci. 2017;124:77-83. https://doi.org/10.1016/j.meatsci.201 6.10 .013$.

28. CIE (CommissionInternationale de l'Éclairage). Recommendations on uniform color spaces-color difference equations, psychometric color terms (supplement no. 2 to CIE publication no. 15). Paris: Commission Internationale de l'Éclairage; 1976.

29. Renna M, Brugiapaglia A, Zanardi E, Destefanis G, Prandini A, Moschini M, et al. Fatty acid profile and meat quality of beef from double-muscled Piemontese bulls fed ground flaxseed. Ital J Anim Sci. 2019;18(1):355-65. https://doi.org/10.1080/1828051X.2018.1530958.
30. Renna M, Lussiana C, Cornale P, Fortina R, Mimosi A. Changes in goat milk fatty acids during abrupt transition from indoor to pasture diet. Small Rum Res. 2012;108:12-21. https://doi.org/10.1016/j.smallrumres.2012.06.007.

31. Palmegiano GB, Daprà F, Forneris G, Gai F, Gasco L, Guo K, et al. Rice protein concentrate meal as a potential ingredient in practical diets for rainbow trout (Oncorhynchus mykiss). Aquaculture. 2006;258(1-4):357-67. https://doi.org/10.1016/j.aquaculture.2006.04.011.

32. Glencross B, Blyth D, Cheers S, Bourne N, Wade N, Irvin S. A compendium of raw material digestibilities for barramundi, Lates calcarifer. Aquac Nutr. 2017; 23:1055-64. https://doi.org/10.1111/anu.12473.

33. Abdel-Tawwab M, Khalil RH, Metwally AA, Shakweer MS, Khallaf MA, Abdel-Latif HM. Effects of black soldier fly (Hermetia illucens L.) larvae meal on growth performance, organs-somatic indices, body composition, and hemato-biochemical variables of European sea bass, Dicentrarchus labrax. Aquaculture. 2020;522:735136. https://doi.org/10.101 6/j.aquaculture.2020.735136.

34. Fawole FJ, Adeoye AA, Tiamiyu LO, Ajala KI, Obadara SO, Ganiyu IO. Substituting fishmeal with Hermetia illucens in the diets of African catfish (Clarias gariepinus): effects on growth, nutrient utilization, haematophysiological response, and oxidative stress biomarker. Aquaculture. 2020; 518:734849. https://doi.org/10.1016/j.aquaculture.2019.734849.

35. Wang G, Peng K, Hu J, Yi C, Chen X, Wu H, et al. Evaluation of defatted black soldier fly (Hermetia illucens L.) larvae meal as an alternative protein ingredient for juvenile Japanese seabass (Lateolabrax japonicus) diets. Aquaculture. 2019; 507:144-54. https://doi.org/10.1016/j.aquaculture.2019.04.023.

36. Elia AC, Capucchio MT, Caldaroni B, Magara G, Dörr AJM, Biasato I, et al. Influence of Hermetia illucens meal dietary inclusion on the histological traits, gut mucin composition and the oxidative stress biomarkers in rainbow trout (Oncorhynchus mykiss). Aquaculture. 2018;496:50-7. https:// doi.org/10.1016/j.aquaculture.2018.07.009.

37. Sealey W, Gaylord T, Barrows F, Tomberlin J, McGuire M, Ross C, et al. Sensory analysis of rainbow trout, Oncorhynchus mykiss, fed enriched black soldier fly prepupae, Hermetia illucens. J World Aquacult Soc. 2011;42:34-45. https://doi.org/10.1111/j.1749-7345.2010.00441.x.

38. laconisi V, Bonelli A, Pupino R, Gai F, Parisi G. Mealworm as dietary protein source for rainbow trout: body and fillet quality traits. Aquaculture. 2018; 484:197-204. https://doi.org/10.1016/j.aquaculture.2017.11.034.

39. Villazana J, Alyokhin A. Development of black soldier fly larvae (Diptera: Stratiomyidae) on seafood wastes. J Insects Food Feed. 2019;5(4):313-9. https://doi.org/10.3920/JIFF2019.0008.

40. Truzzi C, Giorgini E, Annibaldi A, Antonucci M, Illuminati S, Scarponi G, et al. Fatty acids profile of black soldier fly (Hermetia illucens): influence of feeding substrate based on coffee-waste silverskin enriched with microalgae. Anim Feed Sci Technol. 2020;259:114309. https://doi.org/10.1016/j.anifeedsci.201 9.114309 .

41. Ravi HK, Vian MA, Tao Y, Degrou A, Costil J, Trespeuch C, et al. Alternative solvents for lipid extraction and their effect on protein quality in black soldier fly (Hermetia illucens) larvae. J Clean Prod. 2019;238:117861. https:// doi.org/10.1016/j.jclepro.2019.117861.

42. Brinker A, Reiter R. Fish meal replacement by plant protein substitution and guar gum addition in trout feed, part l: effects on feed utilization and fish quality. Aquaculture. 2011;310(3-4):350-60. https://doi.org/10.1016/j.aqua culture.2010.09.041

43. Abbas KA, Mohamed A, Jamilah B, Ebrahimian M. A review on correlations between fish freshness and $\mathrm{pH}$ during cold storage. Am J Biochem Biotechnol. 2008;4(4):416-21. https://doi.org/10.3844/ajbbsp.2008.416.421.

44. Secci G, Mancini S, laconisi V, Gasco L, Basto A, Parisi G. Can the inclusion of black soldier fly (Hermetia illucens) in diet affect the flesh quality/nutritional traits of rainbow trout (Oncorhynchus mykiss) after freezing and cooking? Int J Food Sci Nutr. 2019;70(2):161-71. https://doi.org/10.1080/09637486.2018.14 89529.

45. Vanhonacker F, Pieniak Z, Verbeke W. European consumer image of farmed fish, wild fish, seabass and seabream. Aquac Int. 2013;21:1017-33. https:// doi.org/10.1007/s10499-012-9609-2.

46. Borgogno M, Dinnella C, laconisi V, Fusi R, Scarpaleggia C, Schiavone A, et al. Inclusion of Hermetia illucens larvae meal on rainbow trout (Oncorhynchus mykiss) feed: effect on sensory profile according to static and dynamic evaluations. J Sci Food Agric. 2017;97(10):3402-11. https://doi.org/1 $0.1002 /$ jsfa.8191.

47. Mancini S, Medina I, laconisi V, Gai F, Basto A, Parisi G. Impact of black soldier fly larvae meal on the chemical and nutritional characteristics of 
rainbow trout fillets. Animal. 2018;12(8):1672-81. https://doi.org/10.1017/S1 751731117003421.

48. Reyes M, Rodríguez M, Montes J, Barroso FG, Fabrikov D, Morote E, et al. Nutritional and growth effect of insect meal inclusion on seabass (Dicentrarchus labrax) feeds. Fishes. 2020;5(2):16. https://doi.org/10.3390/ fishes5020016.

49. Gasco L, Gai F, Maricchiolo G, Genovese L, Ragonese S, Bottari T, et al. Fishmeal alternative protein sources for aquaculture feeds. In Feeds for the aquaculture sector (pp. 1-28). Cham: Springer; 2018. https://doi.org/10.1007/ 978-3-319-77941-6_1.

50. Wen J, Jiang W, Feng $L$, Kuang S, Jiang J, Tang $L$, et al. The influence of graded levels of available phosphorus on growth performance, muscle antioxidant and flesh quality of young grass carp (Ctenopharyngodon idella). Animal Nutrition. 2015;1 (2):77-84. https://doi. org/10.1016/j.aninu.2015.05.004.

51. Calder PC. Very long-chain $\mathrm{n}-3$ fatty acids and human health: fact, fiction and the future. Proc Nutr Soc. 2018;77(1):52-72. https://doi.org/10.1017/S002 9665117003950.

52. Ewald N, Vidakovic A, Langeland M, Kiessling A, Sampels S, Lalander C. Fatty acid composition of black soldier fly larvae (Hermetia illucens) - possibilities and limitations for modification through diet. Waste Manag. 2020;102:40-7. https://doi.org/10.1016/j.wasman.2019.10.014.

53. Stanley-Samuelson DW, Jurenka RA, Cripps C, Blomquist GJ, de Renobales M. Fatty acids in insects: composition, metabolism, and biological significance. Arch Insect Biochem Physiol. 1988;9(1):1-33. https://doi.org/10.1 002/arch.940090102

54. Belghit I, Liland NS, Gjesdal P, Biancarosa I, Menchetti E, Li Y, et al. Black soldier fly larvae meal can replace fish meal in diets of sea-water phase Atlantic salmon (Salmo salar). Aquaculture. 2019;503:609-19. https://doi. org/10.1016/j.aquaculture.2018.12.032.

55. Biasato I, De Marco M, Rotolo L, Renna M, Lussiana C, Dabbou S, et al. Effects of dietary Tenebrio molitor meal inclusion in free-range chickens. J Anim Physiol Anim Nutr. 2016;100:1104-12. https://doi.org/1 0.1111/jpn.12487.

56. Ramos MA, Gonçalves JF, Batista S, Costas B, Pires MA, Rema P, et al Growth, immune responses and intestinal morphology of rainbow trout (Oncorhynchus mykiss) supplemented with commercial probiotics. Fish Shellfish Immunol. 2015;45(1):19-26. https://doi.org/10.1016/j.fsi.2015.04.001.

57. He M, Wang KW, Liang X, Fang J, Geng Y, Chem Z, et al. Effects of dietary vitamin $\mathrm{E}$ on growth performance as well as intestinal structure and function of channel catfish (Ictalurus punctatus, Rafinesque 1818). Exp Ther Med. 2017;14(6):5703-10. https://doi.org/10.3892/etm.2017.5295.

58. Quin C, Yang L, Zheng W, Yan X, Lu R, Xie D, et al. Effects of dietary glucose and sodium chloride on intestinal glucose adsorption of common carp (Cyprinus carpio L.). Biochem Biophys Res Commun. 2018;495(2):1948-55. https://doi.org/10.1016/j.bbrc.2017.12.065.

59. Lock ER, Arsiwalla T, Waagbo R. Insect larvae meal as an alternative source of nutrients in the diet of Atlantic salmon (Salmo salar) postsmolt. Aquac Nutr. 2016;22(6):1202-13. https://doi.org/10.1111/anu.12343.

60. Magalhães R, Sánchez-López A, Leal RS, Martínez-Llorens S, Oliva-Teles A, Peres H. Black soldier fly (Hermetia illucens) pre-pupae meal as a fish meal replacement in diets for European seabass (Dicentrarchus labrax). Aquaculture. 2017;476:79-85. https://doi.org/10.1016/j.aqua culture.2017.04.021.

61. Rema P, Saravanan S, Armenjon B, Motte C, Dias J. Graded incorporation of defatted yellow mealworm (Tenebrio molitor) in rainbow trout (Oncorhynchus mykiss) diet improves growth performance and nutrient retention. Animals. 2019;9(4):187. https://doi.org/10.3390/ani9040187.

\section{Ready to submit your research? Choose BMC and benefit from:}

- fast, convenient online submission

- thorough peer review by experienced researchers in your field

- rapid publication on acceptance

- support for research data, including large and complex data types

- gold Open Access which fosters wider collaboration and increased citations

- maximum visibility for your research: over $100 \mathrm{M}$ website views per year

At BMC, research is always in progress.

Learn more biomedcentral.com/submissions 